\title{
Individual Paths to Literacy Engagement: Three Portraits
}

\author{
Tara-Lynn Scheffel
}

Nipissing University

\begin{abstract}
This article examines conceptualizations of engagement during literacy learning within an ethnographic case study of a grade two classroom. Specifically, three student portraits are shared, revealing three unique journeys towards engagement. For Spike, it was a path of success where he often determined the direction. For Jasper, the path was bumpy and filled with compliance rather than involvement. For Avery, the path was elusive and filled with struggle, though not for lack of desire. A framework for literacy engagement is presented that considers four filters through which we perceive and thereby recognize a space for individual paths.
\end{abstract}

Key Words: engagement, literacy, primary education, case study

Tara-Lynn Scheffel, Ph.D. is an Assistant Professor in Education (Language \& Literacy) at Nipissing University. Her research interests are primarily literacy-related with a focus on student engagement during literacy events. Through her research, she aims to give stronger voice to students and teachers in educational research.

Email: taralyns@nipissingu.ca

Brock Journal, Volume 21(2), Spring 2012, pp. 3-21 


\section{Introduction}

In the light that beckons beyond an open door, three young children can be seen in the shadowed reflections. One child stands in the centre, body slightly turned towards the door but eyes facing forward. Another has walked through the door, only one hand remaining in connection with the doorframe. The third child is also turned sideways but is looking away from the door rather than towards it. (Personal reflection, 2005)

Questions of engagement began in my doctoral work as I found myself continually returning to the complexity of literacy and the ways in which educators work within this complexity to build literacy opportunities. It was in this search for understanding that I discovered the image described above, an image that continually gives me purpose. The description is of a painting by Brenda Joysmith titled Discovering Choices, the cover of a book called Engaging Children: Community and Chaos in the Lives of Young Literacy Learners (Allen, Michalove \& Shockley, 1993). It beckoned me into the lives of these children: I wanted to know their names, their stories, their lived experiences. Engagement became more than a "popular catch phrase" (ButlerKisber and Portelli, 2003) as I considered the ways in which these children were engaged in learning. The open doorway became a path to learning that was clearly defined for some while unreachable for others. I wanted to learn what drew some through the door but turned others away. I wondered how to make the door become permeable.

It was in this yearning that my own journey of discovery began, a journey I discuss in this article. I begin by outlining the key works that influenced this study as I sought to learn more about notions of engagement in order to identify theories, concepts, struggles and possibilities for further exploration. Next, I outline the research methods used as I joined a grade two classroom to learn about engagement. From these methods, I invite you to learn more about three students and their individual paths towards engagement. For, I discovered that there are students likened to the above image. Their names are Jasper, Spike and Avery. Their stories not only demonstrate the complexity of engagement but also highlight the role that perception plays in our understandings of engagement. In conclusion, I propose a framework for literacy engagement that builds from and works alongside the portraits, the goal to create a space for ongoing discussion about literacy engagement.

\section{Literature on Engagement}

Before introducing the portraits, this section first takes a broader look at school engagement to set the stage for a closer look at understandings of engagement that are more specific to reading and then, literacy.

\section{School Engagement}

Engagement, generally characterized as the involvement of students with learning, has been a major focus of educational research surveys such as The Programme for International Student Assessment (PISA) and the National Survey of Student Engagement (NSSE). Along with these two larger surveys, a key theme arising within the literature is the role of active and meaningful participation, along with sense of belonging or school membership (Goslin, 2003; Swan, 2003; Rudduck \& Demetriou's, 2003; Newmann, Whelage \& Lamborn, 1992; Mighty, 2007; Willms \& 
Flanagan, 2005). Portelli and Vibert (2002) used the term "curriculum of life" to describe a school-based research project that took place as part of a pan-Canadian national study on student engagement. More than a simple student-centered notion of constructivism, "a curriculum of life centres on the possibilities for the co-construction and co-production of knowledge, rather than on knowledge as simply teacher transmitted or simply student created" (p. 39). As a result, the "hidden" curriculum is not so hidden, and controversial issues that affect the lives of students are taken seriously.

McMahon (2003) presented three conceptions of engagement: (a) teacher as the presenter of material, using interesting and various strategies; (b) teacher as facilitator of material, drawing upon students' interests; and (c) teacher working with students to establish connections beyond the curriculum that relate to student's lived experiences.

McMahon (2003) described this last conception as fitting with Portelli and Vibert's (2002) "curriculum of life." She further explained, "Engagement in this sense is not simply something that one group (educators) imposes on another (students)" (p. 26).

It may be this cyclical nature that led Cothran and Ennis (2000) to warn that "even a quality curriculum guided by a knowledgeable teacher will not result in student learning unless students first are engaged in the learning process" (p. 124). Cothran and Ennis demonstrated that through communication, care, active learning and respect, teachers can bridge the distance between student factors and school factors, helping students towards engagement.

McMahon and Portelli (2004) considered the work of Cothran and Ennis (2000) to be an important contribution to the field but critiqued its linear nature and focus on engagement as something that teachers "do to students" rather than something that is generated together (p. 66). They applauded the effort to capture students' voices but suggested that a closer look at the purposes of engagement and the worthwhileness of the curriculum is needed. Next, I take a closer look at definitions of reading and literacy engagement.

\section{Reading Engagement}

Within the 2000 PISA survey, reading engagement is defined as "students' motivation and interest in reading, and the time students spend reading for pleasure and reading diverse materials" (Willms, 2003, p.8). However, despite a more specific acknowledgement of engagement in relation to reading, the definition remains broad, mostly related to motivation and time-spent on task. Guthrie and Anderson (1999), however, offered a definition of engaged reading that included "...the joint functioning of motivation, conceptual knowledge, strategies, and social interactions during literacy activities" (p. 2). Doing so, they considered the role of instructional contexts in understanding what takes place in engagement. A similar understanding of reading engagement is presented in the 2009 PISA survey but with recognition that other studies, such as Guthrie \& Wigfield (2000) had accounted for greater variance between reading engagement and achievement than the 2000 results found (OECD, 2010, p. 22).

Yet, while Guthrie (2004) acknowledged the idea that engagement is both a result of as well as a contributor to achievement, the concern that arose for me was that the complexity suggested by his model was in danger of being lost within a list of factors that were viewed as easily measurable. For example, Baker, Dreher and Guthrie (2000) outlined design principles for promoting engaged reading that were described as "simply stated prescription(s) for what children need to become engaged and achieving readers" (p. 316). The use of such simple statements suggested that if only these principles are in place, then engagement is certain to 
occur. A focus on the broader context is diminished, as well as what happens if/when these principles do not work for a student. Guthrie (2001) himself, acknowledged the need for further investigations of these complex instructional practices.

\section{Literacy Engagement}

Crediting Smith (1983) with discovering the missing factor of engagement in the learning equation, Cambourne (1988) identified three main principles for engagement. The first involved learners seeing themselves as potential 'doers' of the activities being demonstrated. Second, the skills or knowledge being demonstrated furthered the purposes of the learners' lives. The third principle considered the risk involved in attempting a demonstration and how opportunities for engagement were limited if viewed as unendurable or threatening. An additional fourth principle was that of a significant teacher-student bond.

These principles highlighted specific areas that Cambourne (1988) identified as unacknowledged by behavioural psychologists, who often failed to understand the concept of engagement by confusing it with motivation. As a result, Cambourne elaborated a sociocultural view of learning that emphasized setting the conditions that would increase learner's decisions towards engagement (immersion, demonstration, use, response, expectation, responsibility and approximation). His principles differed from those of Baker et al. (2000) in that they were more than design principles to promote engaged reading. Instead, they offered foundational classroom practices that were conducive to encouraging engagement in literacy learning. The goal of achievement remained, but was results-based rather than focused on measurement.

\section{Research Design}

This research study draws upon the work of Cambourne (1988) and Guthrie (2004), taking a sociocultural, ethnographic approach to the study of engagement that moves beyond conceptual concerns to consider the absence of individual students' experiences in the literature, in particular those of younger students (Scheffel, 2009). The voices I share here are those of grade two students, along with their teacher and parents. I asked, from the subjective viewpoints of teacher(s) and student(s), what constitutes engagement for primary-aged students in literacy learning?

\section{Participants}

A school of over 600 students with 30+ teachers in Southwestern Ontario set the overall context for my observations. Although the school itself had an ethnically diverse population, the class that I studied had only one student of a visible minority. Initial interest was expressed by the school to the university, following which I made contact with the principal who passed my Letter of Information to the primary staff for consideration. Elsewhere, I elaborate this process more fully as I reflect upon the negotiation process between researcher, teacher and students (Scheffel, 2011). 


\section{Research Methods and Data Sources}

Four complementary research methods were used in this study: (a) participant observation, (b) informal conversational interviews and picture-talks, (c) formal teacher interviews/questionnaires, and (d) journaling, both by students and parents. In total, 53 observations days occurred over a period of $31 \frac{1}{2}$ months. Data sources included: field notes, transcribed interviews of all audio taped discussions and interviews, artifacts of student work, photographs of students working, student journals, parent journals, demographic information, and curriculum materials. The focus of this data was first and foremost the literacy events (Dyson, 2003) that were observed during my time in the classroom. Specifically, I sought to understand what drew students to literacy or appeared to turn them away. I looked for signs of meaning-making and the reasons contributing to this (e.g., cultural knowledge, social relations, shared experiential history). As time and space permitted, I spoke with the students to better understand the reasons for their engagement or lack of engagement. This additional step of conversation acted as a cross-referencing technique, where I was able to see how my observations compared to those of the students.

\section{Data Analysis}

My initial observations maintained a broad view of each participating student within the classroom. The journals and field notes contributed to this first level of analysis by allowing for the formation of questions/topics arising as a way of exploring emerging hypotheses. I then identified a focal group of students for a more in-depth study based on these emerging hypotheses, the remaining students providing the backdrop.

The second level of analysis was threefold: first involving reading/rereading for overall understanding in order to share the story taking place within the classroom; second, the coding and development of themes or issues arising where I looked for points of agreement and contradiction with the current literature in order to contribute to evolving definitions of engagement, and; third, the identification of areas of proposed change in relation to building opportunities for greater engagement within literacy learning, as well as research with children.

\section{Three Portraits}

The portraits of Spike, Jasper and Avery offer insight into three unique journeys involving internal and external factors, as well as differing perceptions of achievement and participation. Space does not allow for each portrait to be shared in its entirety but here I offer an overview that I hope will serve as a reflective tool for further discussions about literacy engagement.

\section{Portrait One - Spike}

Spike's short brown hair is not quite as spiky as his selected pseudonym suggests. He has a thirst for knowledge and is likely to approach you each morning to share a fact he has learned or a funny joke he has found in a book. He always has something to say, which gets him in trouble from time to time. During moments when he is caught not paying attention, he will usually admit it, and his teacher will say, "That's one thing I love about you, you're always honest with me." 
Despite this seeming lack of attention, he is often the first to raise his hand with an answer to a question and he is never shy to attempt an unknown word. He is the student most likely to question if something does not seem quite right. Whether you are in authority or not, he will tell you that you are not supposed to talk in the hallway, especially if he has just been told the same. He could be called Mr. Observant. For example, he knows that his teacher is the only left-handed person in the classroom.

Spike comes from a two-parent, middle-class family. He has one younger brother, in Kindergarten. According to his parents, "Spike loves to read. Since he was born, [he] grew up having 2 bedtime stor[ies] pretty much every night." Some nights, however, he will decide to draw instead of read.

Topics written about in his journal range from popular culture (Pokémon, Neopets, popular movies) and video games (X-box, Game Boy and Tamagotchi - a digital pet), to interests related to books and drawing. Within his journal, there are several comments from his teacher cautioning him about a tendency to change topics too quickly. Though he is often one of the first to hand in his journal, the length is not always satisfactory to his teacher.

In September, Spike's parents listed the following interests and goals:

- Interests: Drawing, building with LEGO, playing hockey

- Goals: To have a fun time and learn new things

Spike's Path To Engagement: Baker et al. (2000) describe the heart of engagement as "the desire to gain new knowledge of a topic, to follow the excitement of a narrative, to expand one's experience through print" (p.2). This is Spike. Driven towards discovery, he found spaces within the school day and at home to follow self-initiated literacy activities and to build his literate lifestyle. He is the engaged reader that Baker et al. (2000) go on to describe as drawing "from previous experiences to construct new understandings...goals are met and interests are satisfied" (p. 2). The research process itself served to engage Spike as a co-researcher, sharing his growing understandings throughout the study (Scheffel, 2009). More than any other student in the class, it seemed that Spike set his own path to engagement.

To offer an example, Spike continually expressed an interest in drawing during my visits. In his research journal, he made the following generational connection: “... because my gramie is an artist" (Observation Day 26). In particular, drawing became a venue for exploring the popular culture phenomenon of Pokémon. Not only did he draw favourite characters (Figure 1), but he had also begun the process of designing his own trading card series (Figure 2), which he hoped to market for profit in the future. Spike and his friends had even started a chapter story about the characters he created with the ultimate goal to have their story displayed in the school library.

Unlike Spike's teacher, who often excluded Pokémon and other popular culture discussions, Spike's mother encouraged this exploration. In the parent journal, she recognized this interest as something to be valued:

Spike has enjoyed collecting Pokémon cards for the past two years. His drawings usually resemble Pokémon characters. Spike tells me that he and his friends are going to make their own cards when they're 19... They have lots of interesting names like 'Flame Squirrel." We laminated the cards he made and he is very excited to show them to his friends tomorrow (Observation Day 28). 

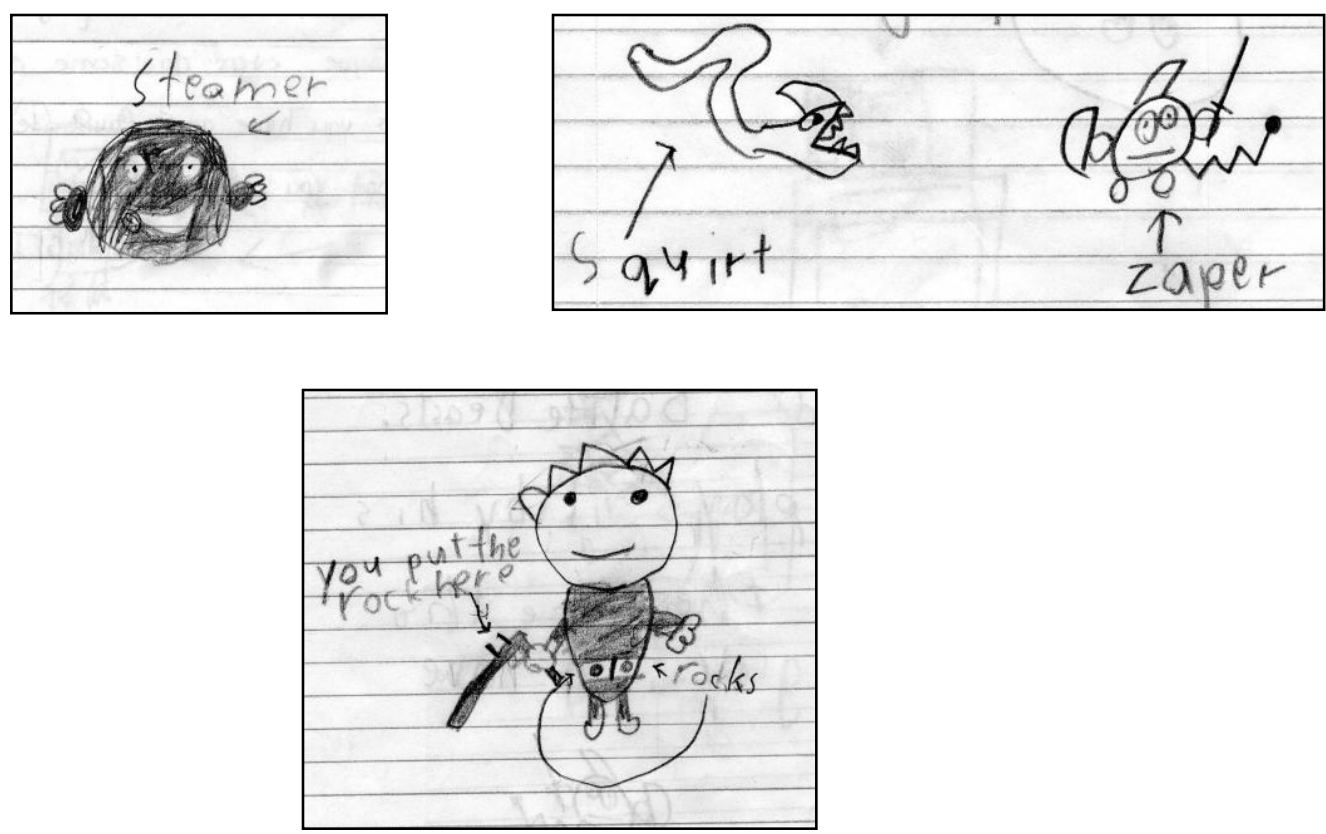

Figure 1. Examples of Spike's 'Alien Pet' characters.

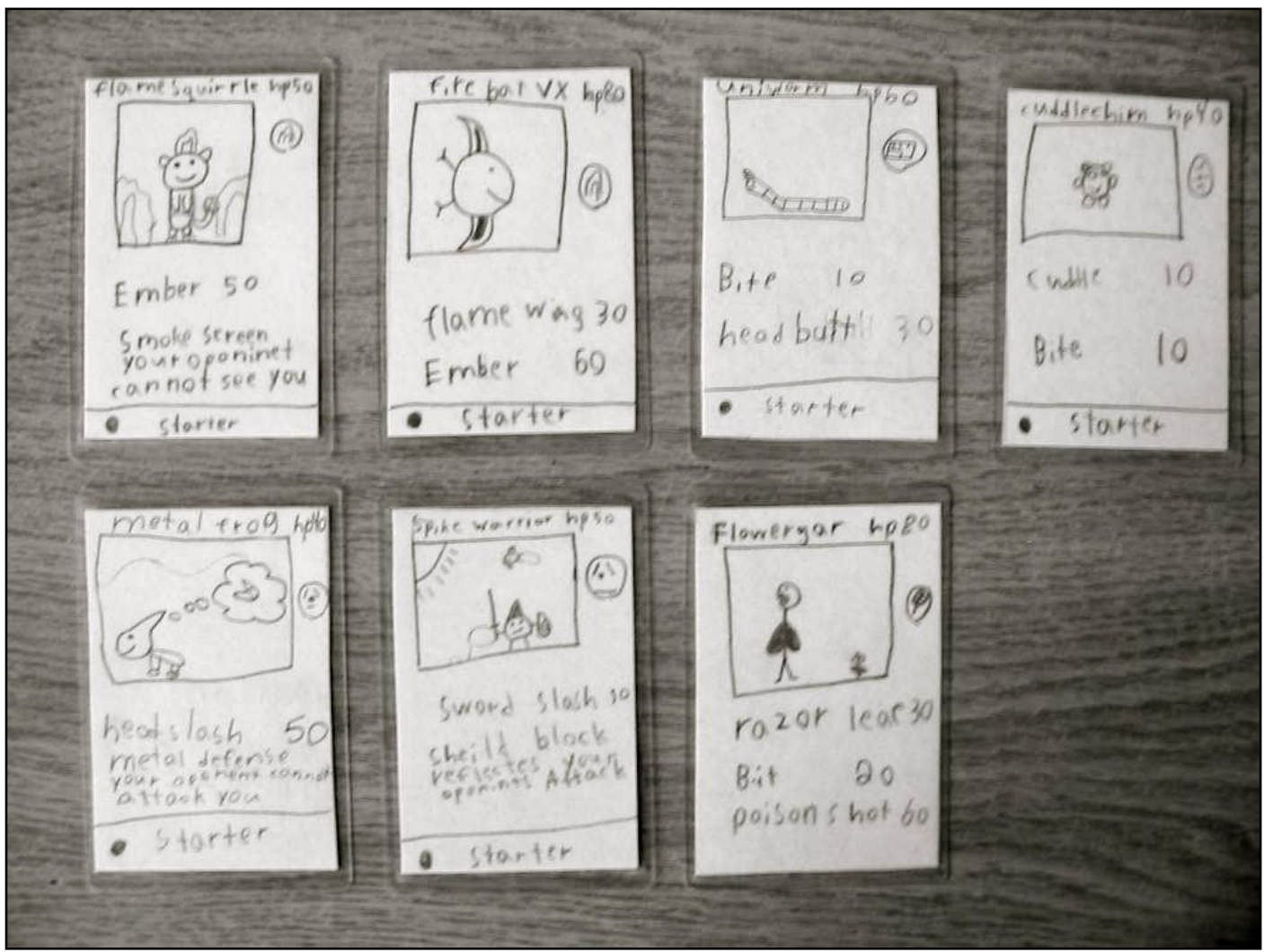

Figure 2. Spike's 'Alien Pet' trading cards 
While concerns over the influence of commercialism may stand out here, what is perhaps more important is the way Spike and his various groups of friends saw purpose in these literacy tasks. The ultimate purpose was one of recognition and success. Vasquez (2003) suggested, "...there is a lot we can learn about how to support literacy development by watching children closely as they engage with such texts" (p.125). Vasquez (2003) described the engagement of Pokémon-related texts by her nephew Curtis and his friends as an open pedagogy that does not privilege only print text. I see a similar pedagogy in Spike's engagement with Pokémon, which may benefit other students if they are allowed to explore popular culture within the school curriculum. Alvermann \& Xu (2003) provided an example of connecting popular culture with a language arts curriculum. They outlined four approaches to using everyday literacies, offering a place for teachers to begin when looking for practical ideas.

Dyson (2001) described a similar open-ended pedagogy in relation to writing. These open times for composing allow educators to, "learn about children's cultural landscapes and the particular voices and kinds of voices that appeal to them." (p. 431). Spike's teacher, Kat, did provide open-ended times for journal writing. However, letting the students know they could write about popular culture interests and include images may have helped to make this time something they looked forward to exploring, rather than a regular, and sometimes mundane, routine.

Through our picture-talks, it was evident that when given ownership over tasks, Spike was most likely to feel engaged. Unlike Jasper and Avery, what stood out was the variety of ways in which Spike found engagement. By academic standards, Spike was the higher achiever of the three. Though his teacher sometimes had greater expectations for his work, knowing he was capable of writing more or going more in-depth, he achieved Grade 2 standards. For Spike, it was a question of effort. When engaged, his desire to participate was stronger. Regardless, he was still able to complete the work. Jasper and Avery's portraits, on the other hand, provide a different consideration of the path to engagement.

\section{Portrait Two - Jasper}

Jasper's tousled blonde hair is reminiscent of a product called Bed Head that allows you to twist your hair in various directions. Jasper too, has a habit of twisting his hair, especially the locks above his left eye.

There is a hoarseness to Jasper's voice that makes it distinct from others. However, he rarely speaks, and when he does, it is often in a soft-spoken, almost whisper. Usually when he is called upon, he says nothing but looks at you. It is hard to know whether the words are there but he is too frightened to let them out, or if his look is a plea to leave him alone. Yet, he speaks to a trusted few classmates, and during these moments, the words seem to flow freely, even excitedly, as moments shared between friends.

When Jasper writes, his head is bent forward, his entire body seemingly placing pressure to the pencil. He is usually several steps behind his classmates when following instructions and maintaining routines. At the end of the day his desk is almost always cluttered with unfinished work or assignments he has forgotten to place inside the drawer.

He has been tested for Central Auditory Processing (CAP) and is on medication for Attention Deficit Disorder (ADD), though his parents find these medications only serve to make 
him more anxious. They believe the origin of his concerns is more related to anxiety rather than attention.

Jasper comes from a two-parent, middle-class family and has a fraternal twin brother, James, who is also in his class. At home they will read together as a family, taking turns. They have also discovered an online book site that both boys love. Their mother concludes, "It seems with these guys at least that the work has to be hidden in play to work best."

Throughout Jasper's journal are many pages where the writing is unfinished or includes only the date and nothing more. It is for this reason, that his teacher finds it difficult to grade his work. Though she feels he is more capable than the lack of completed work suggests, she is torn in the assessment procedures that require her to give him a grade for the work completed.

In September, Jasper's parents listed the following interests and goals:

- Interests: bugs/animals, collecting "things" and toys and make-believe play

- Goals: improve attention, fine motor control, listening skills \& independence

Jasper's Path To Engagement: As I consider Jasper's portrait, I cannot help but think of Cambourne's notion of engagement and the idea of a safe space to take risks. For Jasper, it seems the safest places to speak at school are when he is with his friends. These are the times when he is playful and smiling. With adults however, and at times when he was put on the spot to share or speak, there was a hesitancy, which often resulted in silence. I remember being struck by his adamant words in his first research journal: "I don't like to share my Jernel." The reason why hit me even harder: "because I'm nervise to share it in front of the class" (Observation Day 27). While some students shared freely within the classroom, Jasper did not have this same sense of freedom.

The research journal offered a space where Jasper felt less inhibited: "cause I had nothing to write about in the journal but in this one I could just write about the classroom." His parents shared a similar observation:

He also does not like to write (or at least begin) stories. Once he is into it, and writing about something that interests him, he is better...Jasper, in particular likes non-fiction books dealing with animals. He is very interested in this topic, and it is a great vehicle to get him going or hooked on his work or reading. (Observation Day 18)

Similar interests were noted on the Parent Information sheet in September and with this in mind, having access to books related to animals during journal time might have provided one way to increase his interest in journal writing.

From the perspective of Baker et al.'s (2000) description of engaged readers, Jasper's path is a more perplexing one than Spike's path. His literacy practices at home suggested time for reading books of personal significance with his brother and parents. His parent journal communicated:

We tried something new (for Reading time). We did a "Family Read" where we all sat on the ground around a book and took turns reading. This worked really well as both Jasper and James liked the "both parent" interaction and did not perceive it as work - but rather "fun" time. (Observation Day 18) 
There seemed an investment to participate that was very different from my observation of him at school. His teacher, Kat, was also frustrated by this disconnect, especially when having to evaluate incomplete work at school. She often suspected he was capable, but on a standardsbased curriculum, she needed evidence of completed work during the school day.

Observation Day 36, however, brought about an instance when Jasper overcame this disconnect. The task was to create a game board and while Jasper's initial query to his teacher was an anxious, "Do you have to write anything?", he went on to write a full set of instructions on the back of his game (Figures 3 \& 4). Even Kat commented at the way in which Jasper was drawn into this activity. So, what was it that engaged Jasper? Is it "work hidden within fun" as his parents spoke about in the parent journal? Perhaps it was the interaction of sharing ideas with classmates or the choice of making a game with an open-ended template?

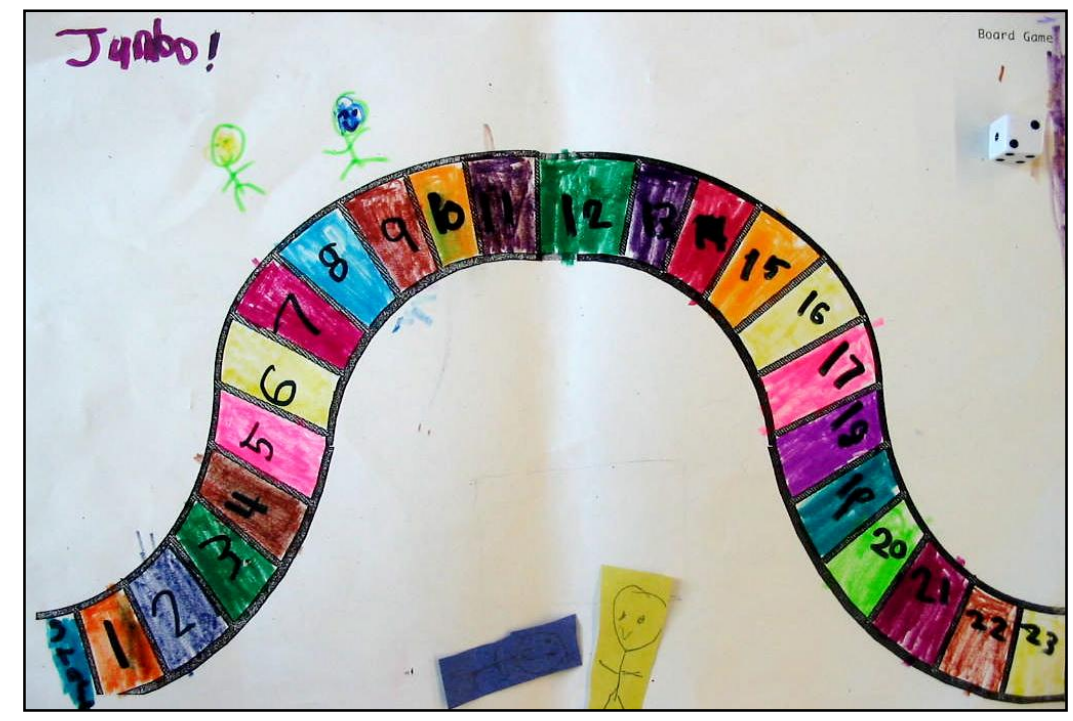

Figure 3. Jasper's Game Jumbo

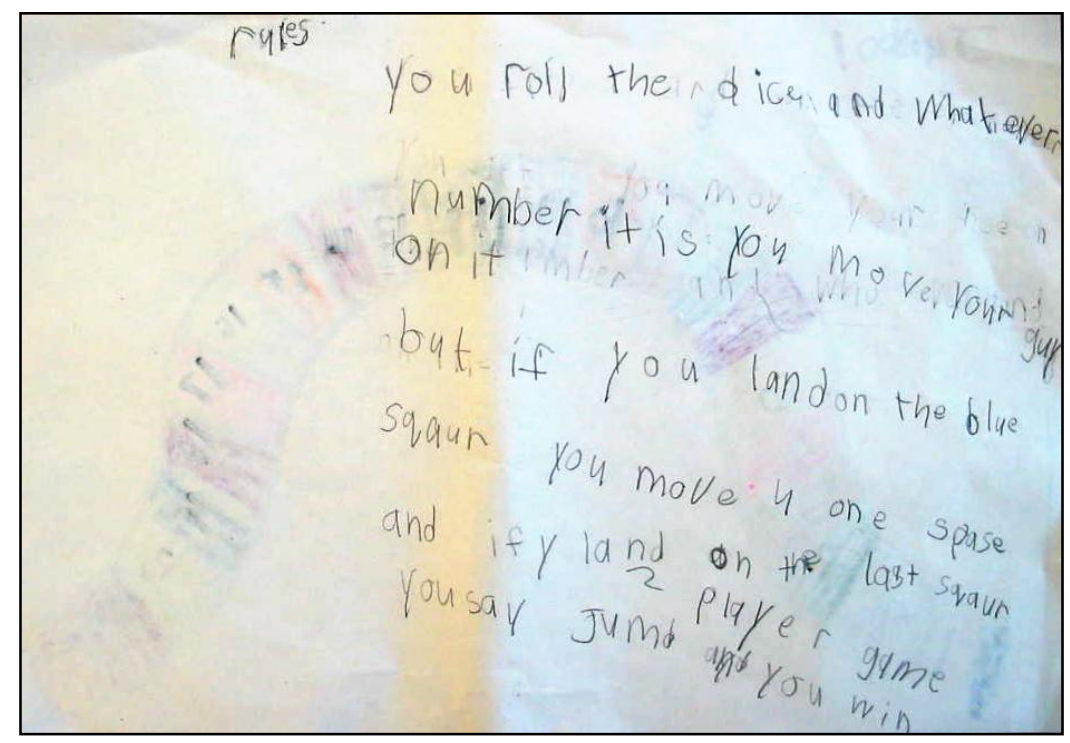

Figure 4. Jasper's instructions on the reverse side of game. 
Our picture-talks reflected a similar sense of action along with a pronounced emphasis on demonstrating participation through focus or concentration, upright body language and raised hands. This is evidenced throughout Jasper's portrait with continued attempts to "look the part." For example one day as we worked together, he grabbed a pencil away from me when Kat walked by his desk. He knew what the expected image of working looked like, and perhaps that independent work held greater influence than shared work. It seemed that Jasper had discovered, as Maxine Greene did in The Dialectic of Freedom (1988), that "below the surfaces there is a whispered reminder that, if an individual plays the game, smiles, and works hard, he/she will be rewarded" (p.15). For Jasper was rewarded when he played the part, whether through stamps or free time privileges. However, though he may have thought he demonstrated work ethic, his paper output provided a different picture. According to Vibert and Shields (2003),

Student engagement is identified with both compliance and involvement. Hence if a child is following instructions, quietly completing a worksheet in math, (and especially if the child is attaining a high percent of correct answers), she or he is considered to be engaged. (p. 226)

What strikes me about Jasper is that he was compliant, just not involved. He did sit at his desk and he made attempts to work. While he did not attain a high percent of correct answers, he provided enough correct answers to demonstrate that he could do the work. His path was perhaps a bumpy one but he was not left behind. He did what was necessary to "get by". For Avery, however, "getting by" was an attainment not easily within her grasp.

\section{Portrait Three - Avery}

Avery has long, blonde hair that occasionally has coloured streaks of dye running through it. Her pale face and slender body evoke the word "fragile." During group activities, she often sits with her knees drawn to her chest with her arms wrapped around her legs. She tends to look downwards, though occasionally she glances up, raising her hand to offer a response. Sometimes she is correct, but more often than not, her teacher guides her to the correct answer. When a class response is called for, Avery waits until she hears her classmates speak collectively, and then joins in, loud and clear, at the end of words.

In writing, Avery seeks constant reassurance. Some of the pages are scribed, while others show assistance in the form of words spelled out at the top of the page. When sharing her work, her voice is quiet and her reading hesitant. She looks to her teacher to help her remember the words on the page but her teacher is not always sure what the words say either. A look at her teacher's grade book reveals few recorded marks. At the beginning of the school year, her teacher requested a speech assessment, which took place late in the spring. As a result, Avery attends weekly sessions with a speech therapist.

When Avery arrives in the morning, she sometimes lays her head down on the desk, as if to suggest that she is not quite ready for the day to start. There are times though, when there is a bounce in her step as she walks. During Library, she bounces in anticipation of an exciting part in a story. When singing in music class, she smiles and bounces along to the beat of the song.

Avery comes from a single parent, working class family. Her father died suddenly when she was in Kindergarten and she rarely speaks of him. She has three older half-siblings, but there appears to be little direct contact with them. She goes to a babysitter's before school, early 
enough that it is the babysitter's responsibility to brush her hair. On the days when her mom works an early morning shift, Avery stays over night at the babysitter's, sleeping on the couch.

In September, Avery's mom listed the following interests and goals:

- Interests: skip and play with her friends;

- Goals: to learn to read and write better.

Avery's Path to Engagement: Baker et al. (2000) suggest that, "Reading engagement is as much a goal for the child struggling to decode words as it is for the proficient reader seeking information for a class project" (p. 3). Avery struggled to decode words and perhaps this struggle makes her path unique from Spike and Jasper's path. Intending to provide cues and support, Kat often centred Avery out publicly by offering verbal modifications that served to lessen or devalue her contributions. For example, Kat began a lesson by saying to another student, “...if you wrote the sentence, 'I saw a black cat', now that would be too easy for you wouldn't it?" He nodded his head and Kat then turned her focus to Avery saying, "but Avery, 'I saw a black cat', or 'I saw a little black cat' would be a good sentence for you' (Observation Day 16). Unaware of these not-so-hidden messages, Kat also sometimes praised others for giving an answer that Avery did not provide when given the chance.

However, the notions of praise for a job well done did not always make Avery feel successful about her work. On Observation Day 9, Avery was upset to discover she still had corrections to make on a story after hearing her teacher say, "Isn't that great. Way to go Avery". Having worked with her the previous day, I had encouraged her to invent spell - that is, not always correcting every word to perfection. Avery then questioned me saying, "But you said it was right yesterday." I realized that I, too, had begun to make these exceptions for Avery. Though Avery was most engaged when she was not held up by the spelling mistakes, the correction process seemed to cancel out her feelings of success, thereby making it a daunting task rather than an engaging one.

My picture-talk with Avery revealed few visual indicators of engagement, mostly looking to the internal indicators of ownership, challenge, and achievement. For example, Avery was the only student who saw herself as not engaged during a Morning Message activity. She explained why as: "Me, because I don't know the sentence". It is perhaps for this reason that visual indicators do not matter to Avery. Why worry about what it looks like to be engaged when engagement seems elusive in relation to achievement?

Vygotsky's (1962/1986) zone of proximal development rings true here as I consider the notion of scaffolding literacy-learning opportunities for Avery. Avery wanted to feel like she was working on level with her class. To her, the learning process was a struggle, not through lack of desire, but because her position along the learning process continuum placed her at the bottom of Grade 2. Avery had already been standing out at this point as someone whose story needed to be shared but this moment solidified the decision for me.

Avery found a momentary sense of belonging when working alongside her best friend. These moments often took place as I was asked to provide guidance as an additional support within the classroom. In this space, I noticed that Avery was no longer the "weaker" student of a large group. She was one of two, and she had something to offer to her best friend. I still remember the moment when she attempted to help her best friend find a Word Wall word. Avery was not held back by what she thought she could not do, but rather was sharing what she knew. 
Cothran and Ennis (2000) remind us that students must be engaged in the learning process in order to gain from a quality curriculum provided by a knowledgeable teacher. Likewise, Mighty (2007), in reference to the NSSE survey, describes the importance of focusing on the process of learning over a strict focus on the content to be taught. Inherent in the process is helping students to make connections to their lives, which allows students to gain mastery over their learning. Avery's portrait reinforces this role of the personal when it comes to engagement. A poignant example took play on Observation Day 12 when Avery was asked to reflect on the people and items that made up her life. She hesitated, sharing "it's only me and my mom." Unknowingly, this activity had emphasized a difference from other students in the classroom, as well as the loss of her father in comparison to the families of her classmates.

Recognizing the bond that had formed between us, I was uncertain at the time if I had contributed to helping Avery find the door or if I had instead, turned her farther away from it. Seeing her growing literacy attempts, however, I knew that I did not turn her farther away. For, as Avery experienced both her best friend leaving and then my departure, she attempted to make sense of how she felt in both verbal and written form. Though her journal entries remained difficult to read at times, when asked, she could read back what she intended to say. There were no comparisons to others but just a need to write to express her thoughts.

Notably, I did not receive a parent journal from Avery's mom and as a result, cannot provide any insight into Avery's literate experiences at home. While some may suggest this is because there is a lack of interest and therefore probably a lack of participation by her mother, I caution that this would be an unfair summarization. I do not know why the journal was not returned. What I do know is that there is nothing to suggest any detriment on the part of Avery's mom in relation to Avery's academic achievement. As a teacher and researcher, the real question is how school can provide a space for literacy engagement.

\section{A Framework for Literacy Engagement}

Through my analysis of these three portraits of Grade 2 students, I learned that perception has a great deal to do with how we as educators view engagement in our students. I propose a framework for literacy engagement (Figure 5) that considers four filters through which we perceive and thereby recognize a space for individual paths: personal, filter, observable visual, and internal senses. Table 1 provides a descriptor for the terms within the filters.

Like Cambourne's (1988) conditions, I envision the framework and accompanying portraits as providing a reminder of the conditions needed for engagement. Teachers might use them as reflective tools for collaborative discussions, lesson planning, observations, and personal growth. Teachers might consider what path makes more sense to them as they reflect upon what they value most as a learner and a student. As a result, we can begin to look more closely at the question of what counts as engagement and by whom, in particular with younger students. Teachers might also use the framework to map the individual paths of their students in relation to their existing assessment procedures, pondering their students' life experiences and funds of knowledge (Gonzalez, Moll \& Amanti, 2005).

Elaborating Cambourne's (1988) fourth principle of engagement, these portraits illustrate the significance of a teacher-student bond. Spike longed for a bond that would allow him to share his love for Pokémon and the many ways this entered his literate lifestyle. For Jasper, the lack of a bond, though not necessarily by anyone's fault, contributed to his lack of communication skills. Finally, for Avery, it seemed that she desired to be recognized for her capabilities, an expectation 
that started from a place of her strengths, rather than limitations. She required an understanding of her identity both within and outside of the classroom, as evidenced by the example of the activity that asked her to recall family and objects in her life, bringing the loss of her father to the forefront.

Thus, the framework can also provide a starting point for asking parents what it is that engages their children during literacy activities at home, moving beyond the parent information letters that teachers often send home at the beginning of the year but do not always investigate more closely as the year progresses. As Heath (1983), Purcell-Gates (1995), Gonzalez, Moll and Amanti (2005) and many others have demonstrated, there is a need to cross the divide between classroom walls and students' homes/communities. Compton-Lilly (2009) conveyed well how this can lead teachers to rethink their assumptions and "listen to families" (p. 457).

For a teacher to be all these things is daunting, perhaps even overwhelming and frightening. Noddings (2005) writes of an ethic of care in relation to moral education and proposes an educational system that will allow care to thrive instead of become lost in a culture of achievement. This proposed system is designed around themes of care as opposed to traditional disciplines. While many educators and policy makers may find it hard to envision such a structure, Noddings (2005) challenges us to reconsider that which will enable care to flourish in an already demanding process of schooling.

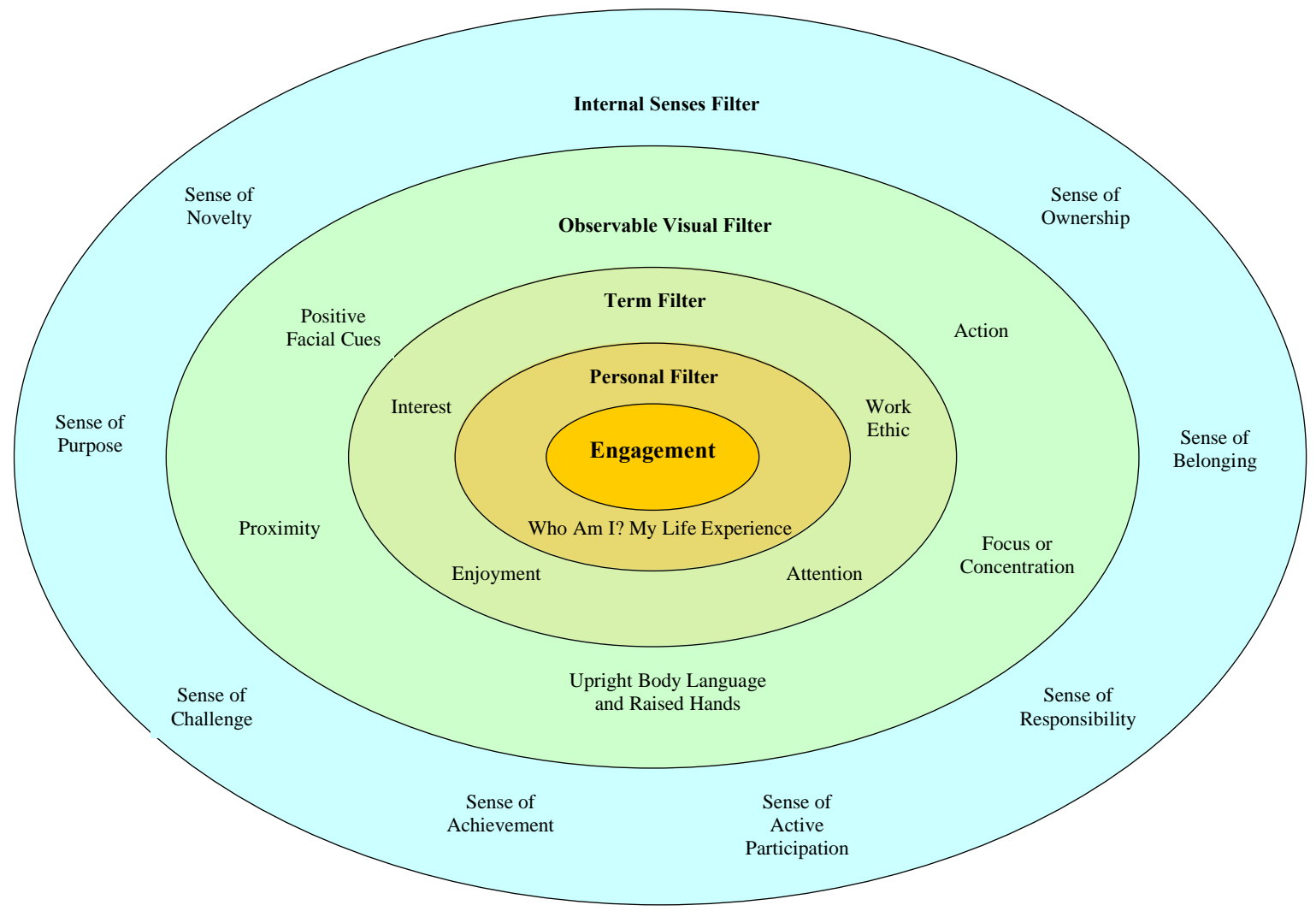

Figure 5. A framework for literacy engagement. 


\section{Table 1}

Description of Terms

\begin{tabular}{|c|c|}
\hline \multicolumn{2}{|l|}{ Observable Visual Filter } \\
\hline Positive Facial Cues & The idea that a smile suggests enjoyment and involvement. \\
\hline Proximity & The understanding that to sit close to the teacher demonstrates a desire to want to learn. \\
\hline $\begin{array}{l}\text { Upright Body } \\
\text { Language/Raised Hands }\end{array}$ & $\begin{array}{l}\text { The reinforced behaviour of sitting upright and raising your hand to demonstrate that you } \\
\text { are both listening and know the answer. }\end{array}$ \\
\hline Focus or Concentration & A gaze that follows the learning taking place. \\
\hline Action & The behavioural sense of action that demonstrates participation. \\
\hline \multicolumn{2}{|l|}{ Internal Senses Filter } \\
\hline Sense of Novelty & $\begin{array}{l}\text { During the daily routine of school, students sometimes want and need some novelty, } \\
\text { whether it is being allowed access to restricted materials, such as markers, or an activity } \\
\text { they have not done before. }\end{array}$ \\
\hline Sense of Purpose & $\begin{array}{l}\text { Students are often looking for personally meaningful activities, ones that connect to their } \\
\text { lives and allow them to work towards a purpose. }\end{array}$ \\
\hline Sense of Challenge & $\begin{array}{l}\text { Students are looking for activities that allow them to grow in their learning process. } \\
\text { These activities often represent an optimum level of challenge that mirrors Vygotsky's } \\
\text { zone of proximal development (ZPD). }\end{array}$ \\
\hline Sense of Achievement & $\begin{array}{l}\text { Students need to know that the activity is not beyond their capabilities and will allow } \\
\text { them to feel success. For those that struggle to meet the curriculum standards, a sense of } \\
\text { achievement or lack thereof, may limit their literacy engagement. }\end{array}$ \\
\hline $\begin{array}{l}\text { Sense of Active } \\
\text { Participation }\end{array}$ & $\begin{array}{l}\text { Students want to be involved in what they are doing, whether it is acting out a Word Wall } \\
\text { word, or opportunities to write and draw as they learn. }\end{array}$ \\
\hline Sense of Responsibility & $\begin{array}{l}\text { For some students, opportunities to lead tasks and take responsibility may contribute to } \\
\text { greater engagement. Creating spaces that are non-threatening, as Cambourne (1988) } \\
\text { suggested, are key to this sense of engagement. }\end{array}$ \\
\hline Sense of Ownership & $\begin{array}{l}\text { Whether through making their own choices or having the freedom to explore personal } \\
\text { ideas, students want opportunities that allow them to have ownership over their learning. }\end{array}$ \\
\hline Sense of Belonging & $\begin{array}{l}\text { For some students, it is the process of working with another that creates a space for their } \\
\text { learning to be fostered. }\end{array}$ \\
\hline
\end{tabular}

Harkening back to Dewey's (1938) progressive education, Dewey too, saw the role of the teacher as significant to the promotion of a child's interests. He proposed a project-based approach that bridged the gap between the curriculum and children's interests. In Early Childhood Education, I see a return to similar notions in the newly outlined Early Childhood curriculum for New Brunswick, a project for which I was a team member. Katz and Chard 
(1992) and Helm and Katz (2000), influential researchers in the field of early childhood, offer concrete ways for teachers to build upon the strengths and interests of their students.

Students, too, can be involved in discussions about engagement. In these discussions with children, the term engagement need not be used. Rather, it is the idea of what leads students to engagement and what makes the learning process one that allows them to walk through the door. I invite researchers as well, to build beyond this work, to add new ideas and connections that highlight more individual stories, in particular those in relation to areas of social justice.

\section{Final Thoughts}

As these brief portraits demonstrate, engagement is complex, and as such, requires an openended conception that allows for individual paths like those of Spike, Jasper and Avery. They teach us that engagement is as individual as the students in the classroom are. It cannot be defined in general terms. It may be necessary to say that student engagement is a good thing, but it is not sufficient to reduce engagement to the lowest common denominator. I leave you once again with the image of the doorway and the three children. I ask you to remember them and the question that remains. How might we, as educators, help each student to find his or her path through the door? 


\section{References}

Allen, J., Michalove, B., Shockley, B. (1993). Engaging children: Community and chaos in the lives of young literacy learners. Portsmouth, NH: Heinemann Portsmouth.

Alvermann, D. \& Xu, S. H. (2003). Children's everyday literacies: Intersections of popular culture and language arts instruction. Language Arts, 81 (2), 145-154.

Baker, L., Dreher, M. J., \& Guthrie, J. T. (2000). Engaging young readers: Promoting achievement and motivation. New York, NY: The Guildford Press.

Butler-Kisber, L., \& Portelli, J. (2003). The challenge of student engagement: Beyond mainstream conceptions and practices. McGill Journal of Education, 38(2), 207-212.

Cambourne, B. (1988). The whole story: Natural learning and the acquisition of literacy in the classroom. Newtown, Australia: Primary English Teachers Association.

Compton-Lilly, C. (2009). Listening to families over time: Seven lessons learned about literacy in families. Language Arts, 86(6), 449-457.

Cothran, D. J., \& Ennis, C. D. (2000). Building bridges to student engagement: Communicating respect and care for students in urban high schools. Journal of Research and Development in Education, 33(2), 106-117.

Dewey, J. (1938). Logic: The theory of inquiry. New York: Holt.

Dyson, A. H. (2001). Donkey Kong in little bear country: A first grader's composing development in the media spotlight. The Elementary School Journal, 101(4), 417-433.

Dyson, A. H. (2003). The brothers and sisters learn to write-Popular literacies in childhood and school culture. New York, NY: Teachers College Press.

Goslin, D. (2003). Engaging minds: Motivation and learning in America's schools. Oxford: Scarecrow Press.

Greene, M. (1988). The dialectic offreedom. New York, NY: Teachers College Press.

González, N., Moll, L., \& Amanti, C. (2005). Funds of knowledge: Theorizing practices in households, communities, and classrooms. Mahwah, NJ: Lawrence Erlbaum.

Guthrie, J. T. (2001, March). Contexts for engagement and motivation in reading. Reading Online, 4(8). Retrieved May, 2008, from http://www.readingonline.org/articles/art_index.asp?HREF=/articles/handbook/guthrie/ index.html 
Guthrie, J. T. (2004). Classroom contexts for engaged reading: An overview. In J. T. Guthrie, A. Wigfield \& K. C. Perencevish (Eds.), Motivating reading comprehension: Conceptoriented reading instruction (pp. 1-24). Mahwah, NJ: Lawrence Erlbaum Associates.

Guthrie, J. T., \& Anderson, E. (1999). Engagement in reading: Processes of motivated, strategic, knowledgeable, social readers. In J. T. Guthrie \& D. E. Alvermann (Eds.), Engaged reading: Processes, practices, and policy implications (pp. 17-45). New York: Teachers College Press.

Guthrie, J. T. \& Wigfield, A. (2000). Engagement and motivation in reading. In M. L. Kamil, P.B. Mosenthal, P.D. Pearson, \& R. Barr (Eds.), Handbook of reading research: Volume III (pp. 403-422). New York: Erlbaum.

Heath, S. B. (1983). Ways with words - Language, life and work in communities and classrooms. New York, NY: Cambridge University Press.

Helm, J. H., \& Katz, L. (2000). Young investigators: The project approach in the early years. New York: Teachers College Press

Katz, L. G. \& Chard, S. C. (1992). Engaging minds: The project approach. Norwood, NJ: Ablex Publishing Corporation.

McMahon, B. J. (2003). Putting the elephant into the refrigerator: Student engagement, critical pedagogy and antiracist education. McGill Journal of Education, 38(2), 257-273.

McMahon, B., \& Portelli, J. (2004). Engagement for what? Beyond popular discourses of student engagement. Leadership and Policy in Schools, 3(1), 59-76.

Mighty, J. (2007). Making it real: Student engagement - An interview with Dr. Joy Mighty. Reflections: Newsletter of the teaching support centre, The University of Western Ontario, 56, p.2.

Newmann, F. M., Wehlage, G. G., \& Lamborn, S. D. (1992). The significance and sources of student engagement. In Fred M. Newmann (Ed.), Student engagement and achievement in American secondary schools (pp. 11-39). New York: Teachers College Press.

Noddings, N. (2005). The challenge to care in schools: An alternative approach to education ( $2^{\text {nd }}$ ed.). New York: Teachers College Press.

OECD (2010). PISA 2009 - Assessment framework: Key competencies in reading, mathematics and science. Retrieved January 2012 from: http://www.oecd.org/dataoecd/11/40/44455820.pdf

PISA (2000). Messages from PISA 2000. Organization for Economic Co-operation and Development. Retrieved April, 2008 from http://www.oecd.org/dataoecd/31/19/34107978.pdf 
Portelli, J. P. \& Vibert, A. B. (2002). A curriculum of life. Education Canada, 42, 36-39.

Purcell-Gates, V. (1995). Other People's Words: The Cycle of Low Literacy. Cambridge, MA: Harvard University Press.

Rudduck, J., \& Demetriou, H. (2003). Student perspectives and teacher practices: The transformative potential. McGill Journal of Education, 38(2), 274-288.

Scheffel, T. (2009). Valuing children's roles in research on literacy engagement. In L. Iannacci and P. Whitty (Eds.), Early Childhood Curricula: Reconceptualist Perspectives (pp.143166). Detselig Press.

Scheffel, T. (2011). Who am I? Who are you? Negotiating a researcher identity. Language and Literacy, 13(2), 54-65.

Smith, F. (1983). Essays into literacy. Exeter, New Hampshire: Heinemann Educational Books.

Swan, E. (2003). Concept-oriented reading instruction: Engaging classrooms, lifelong learners. New York: Guilford Press.

Vasquez, V. (2003). What Pokémon can teach us about learning and literacy. Language Arts, $81(2), 118-125$.

Vibert, A. B. \& Shields, C. (2003). Approaches to student engagement: Does ideology matter? McGill Journal of Education, 38(2), 221-240.

Vygotsky, L. S. (1962/1986). Thought and language. Cambridge, MA: MIT Press.

Willms, J. D. (2003). Student engagement at school: A sense of belonging and participation. Results from PISA 2000. Paris: Organisation for Economic Cooperation and Development. Retrieved April, 2004, from http://www.oecd.org/dataoecd/42/35/33689437.pdf

Willms, J. D., \& Flanagan, P. (2005). Tell Them from Me (TTFM): An online survey. Retrieved May, 2008, from http://www.thelearningbar.com/ttfm/main.php 